\title{
A RELAÇÃO ENTRE HERMETISMO E CRISTIANISMO PRIMITIVO: UMA ANÁLISE DE CRENÇAS HERMÉTICAS NO EVANGELHO DE TOMÉ ${ }^{1}$
}

\section{Relationship between Hermetism and Early Christianity: An analysis of hermetic beliefs in the Gospel of Thomas}

\author{
José Aristides da Silva Gamito*
}

\begin{abstract}
Resumo:
A relação e a possível influência do hermetismo no cristianismo primitivo podem ser verificadas em alusões e em relações intertextuais entre o Evangelho de Tomé e as obras: a coleção de tratados intitulada Corpus Hermeticum e Um Livro Sagrado de Hermes Trismegisto a Asclépio. O mencionado evangelho apócrifo compartilha um material semelhante aos evangelhos canônicos, porém, apresenta as marcas de uma fonte altamente mística e que pode ter sido uma coleção de sentenças herméticas. Neste artigo, discutiremos os temas do autoconhecimento e da ascensão celestial como crenças comuns entre os textos herméticos e o Evangelho de Tomé.

Palavras-chave: Evangelho de Tomé; Hermetismo; Autoconhecimento; Ascensão celestial.
\end{abstract}

\section{Abstract:}

The relationship and possible influence of Hermetism in primitive Christianity can be seen in allusions and intertextual relationships between the Gospel of Thomas and the two hermetic works: Corpus Hermeticum and A Holly Book of Hermes Trismegistus addressed to Asclepius. This apocryphal gospel shares a similar source material with the canonical gospels, however, it bears the marks of a highly mystical source and may have been a collection of hermetic sentences. In this paper, we discuss the subjects of self-knowledge and heaven ascent as common beliefs between two hermetic texts and the Gospel of Thomas.

Keywords: Gospel of Thomas; Hermetism; Self-Knowledge; Heaven Ascent.

\section{Introdução}

A discussão que propomos neste artigo tem como enfoque a relação entre o cristianismo antigo e o hermetismo. Esta relação pode ser identificada a partir do Evangelho de Tomé que é um dos textos do cristianismo primitivo que já suscitou diversas leituras, dentre as quais, destacamos as análises dos pesquisadores Gilles Quispel e April DeConick. Eles estabelecem uma relação textual

1 Enviado em: 23.05.2018. Aceito em: 25.05.2020.

* Bacharel e licenciado em Filosofia. Especialista em Docência do Ensino Básico e no Ensino Superior; Língua Latina e Filologia Românica. Mestre em Ciências das Religiões pela Faculdade Unida de Vitória, Vitória/ES; Professor de Teoria do Conhecimento no Seminário Diocesano Nossa Senhora do Rosário, Caratinga-MG. E-mail: joaristides@gmail.com

Protestantismo em Revista | São Leopoldo | v. 45, n. 02 | p. 124-133| Jul./dez. 2019

Disponível em: <http://periodicos.est.edu.br/index.php/nepp> 
e, principalmente, temática entre as crenças do hermetismo e o Evangelho de Tomé. Isto significa a possível influência de uma fonte pagã sobre um texto da tradição dos evangelhos.

Pelo menos, duas crenças básicas do hermetismo aparecem na coleção de sentenças do Evangelho de Tomé: $O$ autoconhecimento como condição de salvação e a possibilidade de viagens ao mundo divino. Há também outras alusões a crenças herméticas no Evangelho. $O$ tema do autoconhecimento é tratado pelos logia 67 a 70 e Quispel percebe nestes textos a influência do pensamento hermetista. ${ }^{3}$ Segundo DeConick, a influência do hermetismo aparece nos logia 13, 82, 83 e 108 através das alusões à ascensão aos céus. Estes textos demonstram que os cristãos tomasinos tinham conhecimento do misticismo de herança judaica e hermética. ${ }^{4}$

Para compreender as possíveis relações entre hermetismo e cristianismo, analisamos as alusões no Evangelho apócrifo de Tomé e duas obras do hermetismo que são o Poimandres e Um Livro Sagrado de Hermes Trismegisto a Asclépio. O Poimandres é o título do primeiro tratado do Corpus Hermeticum e Asclépio é um livro de Hermes endereçado a Asclépio. Na versão inglesa de Brian Copenhaver, este segundo é inserido após os 17 tratados do Corpus Hermeticum. ${ }^{5}$ A literatura hermética é um conjunto de textos com características comuns que contém diálogos, revelações e epístolas de Hermes Trismegisto ou de seus discípulos Tat, Asclépio, Ámon, Ísis e Hórus. O mestre de Hermes aparece sob o nome de Poimandres. São textos sapienciais que envolvem a influência de múltiplas correntes filosóficas e religiosas do mundo antigo como platonismo, estoicismo e neopitagorismo. ${ }^{6}$

A literatura hermética era inicialmente considerada como resultado de um gnosticismo pagão, mas a descoberta de textos herméticos em Nag Hammadi, no Egito, leva-nos a concluir que essas obras pertenciam a monges cristãos e que estes tinham interesse nesse tipo de leitura esotérica. Esses textos que tratam dos ensinamentos de Hermes mostram a via da imortalidade através de rituais de iniciação, do processo de renascimento e a experiência de ascensão aos céus. É possível que existissem comunidades que seguiam esses rituais no Egito até o século IV. ${ }^{7}$

Historicamente, é difícil determinar relações pessoais entre cristãos e herméticos. Mas podemos identificar um interesse nos textos herméticos por parte de alguns cristãos para fins de estratégias de convencimento dos pagãos intelectuais nas atividades de evangelização. Lactâncio e Dídimo, o Cego, se interessaram pela leitura de textos herméticos. Os cristãos se interessaram por alguns conceitos comuns ao cristianismo e na biblioteca de Nag Hammadi foram encontrados três tratados herméticos juntamente com textos cristãos: ${ }^{8}$ O Discurso sobre Oitavo e o Nono (NHC VI,

2 Os termos logion "dito" (plural, logia) referem-se às subdivisões editoriais do Evangelho de Tomé. Cada logion corresponde a uma declaração de Jesus nessa obra. Todo o texto está dividido em 114 logia. Seguimos a seguinte tradução do Evangelho de Tomé: KUNTZMANN, Raymond; DUBOIS, Jean-Daniel. Nag Hammadi: O Evangelho de Tomé: textos gnósticos das origens do cristianismo. Tradução de Álvaro Cunha. São Paulo: Paulinas, 1990.

3 QUISPEL, Gilles. The Gospel of Thomas Revisited. In: VAN OORT, Johannes. Gnostica, Judaica, Catholica: Collected Essay of Gilles Quispel. Nag Hammadi \& Manichaean Studies. V. 55. Leiden; Boston: Brill, 2008, p. 223.

4 DECONICK, April. Seek to See Him: Ascent and Vision Mysticism in the Gospel of Thomas. Leiden; New York: Brill, 1996, p. 109.

5 COPENHAVER, Brian P. Hermetica: The Greek Corpus Hermeticum and the Latin Asclepius in a new English translation, with notes and introduction. Cambridge: Cambridge University Press, 2000. Verificamos três versões da obra Asclépio: uma latina (utilizada por Copenhaver), uma armênia e uma copta (códice de Nag Hammadi VI, 8).

6 BULL, Christian H. Ancient Hermetism and Esoterism. Aries, Journal for the Study of Western Esotericism, v. 15, 2015, p. 109-135.

7 BULL, Christian H. Hermes between Pagans and Christians: The Nag Hammadi Hermetica in Context. In: LUNDHAUG, Hugo; JENOTT, Lance. The Nag Hammadi Codices and Late Antique Egypt. Studien und Texte Antike und Christentum, v. 110. Tübingen: Moher Siebeck, 2018, p. 207-230.

8 BULL, 2018, p. 230-244.

Protestantismo em Revista | São Leopoldo | v. 45, n. 02 | p. 124-133| Jul./dez. 2019

Disponível em: <http://periodicos.est.edu.br/index.php/nepp> 
6), Prece de Ação de Graças (NHC VI, 7) e o Asclépio (NHC VI, 8). ${ }^{9}$ Eles fazem parte do Códice VI descoberto no Egito juntamente com o Evangelho de Tomé. ${ }^{10}$

Os textos que estamos discutindo tiveram a sua origem no Egito. O Evangelho de Tomé, em sua versão copta, foi descoberta no sul daquele país. Porém, há consenso de que ele foi escrito na Síria, em siríaco, e depois levado para o Egito. Trata-se de um evangelho apócrifo do gênero "evangelho de sentenças". ${ }^{11}$ Esta coleção de 114 sentenças atribuídas a Jesus foi composta entre 50 e 140 d. C. ${ }^{12}$ O Evangelho de Tomé compartilha um material semelhante aos evangelhos canônicos, especificamente da fonte $Q$. Mas contém temas que são estranhos à ortodoxia do Novo Testamento e acentuadamente místicos. Neste ponto, entram várias discussões acerca da origem deste misticismo, a hipótese da influência do hermetismo é uma delas. Portanto, o Evangelho de Tomé poderia ter sofrido uma camada redacional posterior no Egito.

Antes de avançarmos nos conceitos herméticos que influenciaram o mencionado Evangelho, identifiquemos as obras em questão. A primeira obra é o primeiro tratado do Corpus Hermeticum, o Poimandres, que foi datado como sendo do final do século I ao início do século II depois de Cristo. A segunda obra é Um Livro de Hermes Trismegisto a Asclépio que foi considerada mais antiga, podendo ser datada do século I depois de Cristo ou até mesmo do século I antes de Cristo. As duas composições herméticas são anônimas, foram escritas em grego e tiveram sua origem na maior parte no Egito. ${ }^{13}$ São estes textos que colocamos em relações intertextuais com o Evangelho de Tomé e analisamos como estas fontes entraram em contato com a tradição tomasina e o consequente sentido teológico dessas crenças. Este contato pode teria ocorrido em duas etapas: ou na camada redacional do Evangelho de Tomé na Síria ou na camada redacional ocorrida no Egito.

\section{A relação entre hermetismo e cristianismo em Edessa, na Síria}

A hipótese da multicamada autoral do Evangelho de Tomé explica como uma tradição textual sobre Jesus se difundiu desde Jerusalém, passando pela Síria e foi encontrada no códice de Nag Hammadi no Egito. O encontro entre o texto de Tomé o hermetismo pode ter ocorrido na Síria, ambiente de redação, ou no Egito, ambiente de recepção do texto. Considerando que a Síria é o ambiente mais provável para a redação do Evangelho de Tomé, procuramos estabelecer uma relação entre a Síria antiga e o hermetismo. As tradições sobre o apóstolo Tomé são originárias daquela região. ${ }^{14}$

A origem do Evangelho de Tomé na região leste da Síria é perfeitamente plausível. O lugar específico de consenso entre os pesquisadores da composição deste evangelho é Edessa, capital do Reino de Osroena. Este reino ficava no limite do Império Romano e era influenciado pelas culturas

9 A sigla NHC (Nag Hammadi Codices, em inglês) corresponde à coleção de códices descoberta em Nag Hammadi, no Egito. O tratado Asclépio de Nag Hammadi é uma versão copta parcial do Asclépio preservado em latim.

10 Os três tratados podem ser encontrados na coletânea: ROBINSON, James (ed.). The Nag Hammadi Library in

English. Leiden: Brill, 1977. Para os demais tratados do Corpus Hermeticum, seguimos a coletânea de Brian Copenhaver.

11 Para um conhecimento específico do gênero do Evangelho de Tomé, recomendo o seguinte artigo: GAMITO, José Aristides da Silva. Discutindo o gênero do Evangelho de Tomé: Os Evangelhos de Sentenças. Reflexus, ano XII, n. 20, 2018, p. 419-435.

12 PATTERSON, Stephen J. The Gospel of Thomas and Christian Origins: Essays on the Fifth Gospel. Leiden; Boston: Brill, 2013, p. 11-14.

13 DEN KERCHOVE, Anna Van. La voie d'Hermès: Pratiques rituelles et traits hermétiques. Leiden; Boston: 2012 p. 5-6.

14 STORI, Eliana. Tommaso in Siria: La Ricenzione del Vangelo secondo Tommaso nella Letteratura Cristiana di Siria (IIV secolo). Università degli Studio di Torino, 2010, p. 42-43.

Protestantismo em Revista | São Leopoldo | v. 45, n. 02 | p. 124-133| Jul./dez. 2019 
da Pérsia e da Índia. As figuras mais importantes do cristianismo originário de Edessa são pouco ortodoxas: Marcião, Bardesanes e Mani. Havia a presença de judeus da diáspora, de diversos grupos cristãos e de cultos pagãos. Os cristãos edessenos no século II eram divididos em marcionitas, bardesanitas, elquesitas, valentinianos e tomasinos. ${ }^{15}$

As características comuns da teologia apresentada no Evangelho de Tomé, nos Atos de Tomé e no Livro de Tomé, o Contendor, indicam a existência de um grupo de cristãos siríacos que compartilhavam as mesmas crenças. A tradição tomasina era a forma de cristianismo mais antiga de Edessa. A presença do apóstolo Tomé naquela região serviu de inspiração para este grupo pioneiro. Este cristianismo tomasino era místico e ascético, com ênfase no conhecimento, na iluminação e na deificação do crente. A existência de uma tradição cristã que venerava Tomé na Síria é um fato inegável, porém, a comprovação de uma comunidade tomasina encontra resistência por parte de alguns pesquisadores da área como Risto Uro e Phillip Sellew. Mas, conforme, conclui Stori: "A presença do nome de Tomé e certa reivindicação de sua figura e sua autoridade em todos estes escritos é um dado que indica a existência de uma tradição vinculada ao seu nome". ${ }^{16}$

Dentro do ambiente multicultural de Edessa, constata-se a presença do hermetismo. Os escritos herméticos tiveram origem em Alexandria, no Egito, e no século II já eram conhecidos em Edessa. As evidências arqueológicas demonstraram que os sabianos, um grupo hermetista, construíram um templo em Harrã próximo de Edessa. O hermetismo atraiu muitos adeptos e levou à retomada do culto do deus Nebo na região, inclusive, chegando a identificá-lo com Hermes. ${ }^{17}$

$O$ contato entre o hermetismo e a literatura desenvolvida naquela região pode ter ocorrido por causa do compartilhamento de alguns conceitos. A concepção de homem na obra de Taciano possui uma semelhança com os escritos herméticos e a crença no destino em Bardesanes de Edessa tem uma visão em comum com o Poimandres. Esta influência hermética na literatura siríaca antiga inclui também uma relação com o Evangelho de Tomé. Gilles Quispel sugere um paralelismo entre Bardesanes e este Evangelho. ${ }^{18}$

\section{O conceito hermético de autoconhecimento e o logion 67}

Gilles Quispel sugeriu que o autor do Evangelho de Tomé utilizou uma coleção de sentenças pagã com teor hermético. O pesquisador demonstrou que Um Livro Sagrado de Hermes Trismegisto a Asclépio têm relações intertextuais com a obra de Tomé. A temática do autoconhecimento é um ponto comum entre os dois textos. ${ }^{19}$ Os cristãos encratistas de Edessa, provavelmente, conheciam alguma coleção de sabedoria hermética. A presença do hermetismo pode ser inferida na região de Edessa e de Harrã. Os escritos de Bardesanes e de Taciano possuem um fundo hermetista. Os escritos herméticos que tiveram a origem em Alexandria já tinham sido difundidos no século II, em Edessa. ${ }^{20}$

Quispel considerou o tema do autoconhecimento no Evangelho de Tomé como um traço da influência do hermetismo. A hipótese explicaria a inclusão desta temática estranha aos demais evangelhos em Tomé. Há um material tomasino que não possui paralelo entre os ditos (logia) de

15 STORI, Eliana. Edessa, la città benedetta: alcune note sui primi gruppi cristiani in Siria. Annali di Storia del'Esegesi, v. 29, n. 1, 2012, p. 49-61.

16 STORI, 2012, p. 49-61.

17 QUISPEL, 2008, p. 220-222.

18 QUISPEL, 2008, p. 222.

19 QUISPEL, 2008, p. 218.

20 QUISPEL, 2008, p. 220-222.

Protestantismo em Revista | São Leopoldo | v. 45, n. 02 | p. 124-133| Jul./dez. 2019

Disponível em: <http://periodicos.est.edu.br/index.php/nepp> 
Jesus da tradição canônica. ${ }^{21}$ Segundo Hartin, os logia formam uma sequência que tem como preocupação o autoconhecimento. ${ }^{22}$ o logion 67 diz: "Quem conhece o Todo, ao privar-se (do conhecimento) de si mesmo, está privado do Todo". ${ }^{23}$ Para o leitor habituado com os evangelhos canônicos, uma asserção como essa soa estranha e enigmática. Para o autor de Tomé, a ausência do conhecimento de si mesmo representa uma privação da totalidade do conhecimento.

Se o logion 67 tivesse sido escrito por um dos evangelistas canônicos, talvez ele soasse como Marcos 8, 36: "Pois, que adianta ao homem ganhar o mundo inteiro, mas perder a sua alma?". A principal diferença é que nos evangelhos canônicos existe uma preocupação com a salvação, já no Evangelho de Tomé o enfoque se dá no autoconhecimento. Assim o autoconhecimento é decisivo para a fé do discípulo tomasino. O logion 69 sugere que o conhecimento consiste no conhecimento do Pai na verdade. O logion induz à conclusão de que este conhecimento conduz à salvação e à vida.

A primeira intertextualidade sugerida por Quispel ocorre entre o logion 67 e a máxima de número 34 de Um Livro Sagrado de Hermes Trismegisto a Asclépio que diz "quem se conhece, conhece o Todo". ${ }^{24}$ Os dois textos fazem a mesma afirmação de que o autoconhecimento é uma condição para o conhecimento do Todo. A obra Poimandres, 18, traz uma menção ao conhecimento: "... e quem se encontre dotado de intelecto e se reconheça como mortal, que o desejo é a causa da morte e que conheça tudo quanto existe". ${ }^{25}$

Quispel considera que essas sentenças já circulavam através de escritos herméticos e que receberam uma edição no Evangelho de Tomé. Uma sabedoria anterior ao texto do evangelho foi adaptada ao conteúdo da fé cristã. Evangelho de João também apresenta uma recepção sapiencial. A versão do logion 3 no Oxyrhynchus Papyrus 654 é uma variação do mesmo tema do autoconhecimento das fontes herméticas: "Aquele que conhece a si mesmo, o encontrará (o Reino dos Céus)". Essas relações intertextuais indicam que os textos herméticos eram conhecidos na região de Edessa e tiveram contato com o Evangelho de Tomé. ${ }^{26}$

O Corpus Hermeticum e o Evangelho de Tomé convergem quanto à importância do autoconhecimento. Aquele que se conhece avança na direção do divino $(\mathrm{CH} 1,21)$. $\mathrm{O}$ texto expõe que a origem do homem é a divindade. A via para se dirigir à vida passa pelo conhecimento: “... aquele que está dotado de intelecto reconheça a si mesmo" $(\mathrm{CH} \mathrm{1,21).} \mathrm{O} \mathrm{retorno} \mathrm{à} \mathrm{origem} \mathrm{divina}$ do homem depende da consciência de sua natureza. ${ }^{27}$

O autoconhecimento que se celebrizou na máxima de Delfos "Conhece-te a ti mesmo", foi interpretado por médio-platônicos, estoicos e hermetistas. O autoconhecimento como transcendência do ego humano rumo à divindade tornou-se um topos recebido também dentro da tradição de Jesus. ${ }^{28} \mathrm{O}$ logion 67 tem o autoconhecimento em grande apreço porque aquele que

21 QUISPEL, 2008, p. 223.

22 HARTIN, Patrick J. The Search for the True Self in the Gospel of Thomas, the Book of Thomas and the Hymn of the Pearl. HTS Theological Studies, Durbanville, 55, 4, 1999, p. 1001-1021.

23 KUNTZMANN; DUBOIS, 1990, p. 57.

24 MAHÉ, Jean Pierre. Les Definitions d'Hermès Trismegiste à Asclépius. Revue des Sciences Religieuses, t. 50, f. 3, 1976, p. 193-214.

25 COPENHAVER, Brian P. Hermetica: The Greek Corpus Hermeticum and the Latin Asclepius in a new English translation, with notes and introduction. Cambridge: Cambridge University Press, 2000, p. 115.

26 QUISPEL, 2008, p. 218-221.

27 COPENHAVER, 2000, p. 115.

28 PATTERSON, Stephen. The Gospel of Thomas and Christian Origins: Essays on the Fifth Gospel. Leiden: Brill, 2013, p. 37.

Protestantismo em Revista | São Leopoldo | v. 45, n. 02 | p. 124-133| Jul./dez. 2019

Disponível em: <http://periodicos.est.edu.br/index.php/nepp> 
conhece o Todo, mas não conhece a si mesmo, na verdade, não conhece o Todo. Este autoconhecimento se conecta com a iluminação e conduz o homem à deificação.

\section{A experiência das ascensões celestiais no Corpus Hermeticum e no Evangelho de Tomé}

April DeConick também aponta uma relação entre o Evangelho de Tomé e o Corpus Hermeticum. Comum a ambas as obras é a visão divina e a ascensão aos céus. De acordo com o Corpus Hermeticum 10, a experiência de visões transforma um ser humano em outro. No hermetismo a mística transformadora está relacionada à experiência de visão: "Encheste-nos com uma visão, pai, que é boa e muito bela: o olho da mente está quase (cego) por esta visão." 29 Segundo o logion 84, a luz do Pai desvela as imagens que se manifestam ao homem. A promessa de revelação percorre várias sentenças do Evangelho, a começar pelos dois primeiros logia. Os ensinamentos de Jesus estão plenos de vida e quem interpretar as suas palavras não conhecerá a morte (logion 1) e reinará sobre o Todo (logion 2). No logion 17, Jesus promete aos seus discípulos uma experiência espiritual ímpar ao afirmar: "Eu vos darei o que os olhos não viram e o que as mãos não tocaram e [o que] não subiu ao coração do homem".

As experiências místicas da teologia tomasina são a união do ego, a iluminação intelectual e a identificação com o divino. São temas com uma linguagem e um conceito muito próximos não somente do círculo hermético, mas também do médio-platonismo. A visão descrita tanto no Corpus Hermeticum como no Evangelho de Tomé utiliza a linguagem da luz. No logion 83, Jesus identifica o lugar de sua presença como o lugar do fogo e aquele que está próximo dele, consequentemente, está próximo do Reino dos Céus. De fato, Jesus instrui os seus discípulos a identificarem como oriundos da luz (logion 50). O fogo é associado às noções herméticas de ascensão e visões transformadoras. Em CH 10, 4, a visão é descrita por Tat como uma experiência bela e com uma luz intensa que quase chega a cegar os olhos. Porém, ela não causa dano a quem faz esta experiência, ao contrário, está cheia de imortalidade. $O$ estado de quem passa pela experiência é semelhante ao sono e sai do corpo até uma visão mais bela. ${ }^{30}$

A experiência mística descrita no Corpus Hermeticum provoca um estado de repouso, de esquecimento dos sentidos ("quem entendeu não pode entender mais nada, nem quem viu, ver mais nada") e ilumina completamente a alma elevando o corpo ao alto ("através do corpo a [alma] arrasta ao alto") (CH 10, 6). No alto, a alma observa a beleza do bem, porém, enquanto estiver conectada ao corpo não pode atingir a deificação ("Pois embora a alma tenha observado a beleza do bem, filho meu, não pode ser deificada enquanto permaneça no corpo humano"). O Evangelho de Tomé é perpassado por um desejo de busca que culmina no repouso, segundo a versão do Papyrus Oxyrhynchus 654: "Aquele que procura não cesse [de buscar], ele encontrará e quando encontrar, ele ficará [admirado], então, ele reinará, depois de ter reinado, repous[ará]." ${ }^{\prime 1}$

A experiência mística do $\mathrm{CH} 10$ traz suas semelhanças com a contemplação do bem do platonismo. A visão do bem provoca uma iluminação que, em vez de cegar, permite receber o esplendor intelectual. Em CH, a visão é descrita em dois estágios. Primeiramente, o crente poderá contemplar o bem, e depois, "aqueles que são capazes de beber mais profundamente da visão", saem de seus corpos para experimentar uma visão ainda mais bela. De algum modo, este misticismo que envolve também o Evangelho de Tomé vai se tornar comum nas tradições místicas do

29 COPENHAVER, 2000, p. 148.

30 COPENHAVER, 2000, p. 148.

1 Trata-se da versão do logion 2.

Protestantismo em Revista | São Leopoldo | v. 45, n. 02 | p. 124-133| Jul./dez. 2019

Disponível em: <http://periodicos.est.edu.br/index.php/nepp> 
cristianismo medieval, basta conferir as obras do Pseudo-Dionísio Areopagita e sua influência posterior nos místicos europeus.

O divino se contempla quando as palavras não são mais suficientes. O conhecimento do bem é o silêncio divino e a supressão dos os sentidos ( $\mathrm{CH} 10,5)$. No logion 13 do Evangelho de Tomé, o apóstolo Tomé recebe uma revelação particular de Jesus e não ousa dizer aos seus companheiros o conteúdo da experiência. Quando Jesus pergunta aos seus discípulos com quem ele se assemelha, a resposta de Tomé já tem uma conotação de inefabilidade: "Mestre, minha boca não aceitará de modo algum dizer a quem te assemelhas" (logion 13). A experiência mais profunda tanto do misticismo hermético quanto do tomasino culmina na inefabilidade e no silêncio da contemplação.

No tratado hermético Poimandres, a experiência se aprofunda da visão mística até uma viagem celestial. Neste texto, a alma viaja até o oitavo céu. A experiência de Pimandro tem como propósito o conhecimento e a deificação. O narrador do $\mathrm{CH}$ 1, afirma a Pimandro que deseja conhecer todas as coisas, compreender sua natureza e conhecer Deus $(\mathrm{CH} 1,3)$. A visão que abriu foi infinita e de uma luz que envolveu tudo $(\mathrm{CH} 1,5)$. Então, Pimandro explica a natureza de todas as coisas. Dentro da tradição hermética, o acesso ao reino divino serve para legitimar a sabedoria como profunda revelação. ${ }^{32} \mathrm{~A}$ divisão do céu em camadas não encontra correspondência na literatura grega, essa influência vem das tradições apocalípticas judaicas. O número de céus não é preciso. Os apocalipses fazem referência a três, cinco e sete céus. Paulo menciona no Novo Testamento o terceiro céu (2 Cor 12, 2). O número sete é o mais comum, porém, o autor de Poimandres no intuito de introduzir uma experiência mística mais profunda acrescenta o oitavo céu. Em 2 Enoque, aparece um raro exagero que é a menção de um décimo céu. ${ }^{33}$

O oitavo céu de Poimandres é o destino final da alma que faz a experiência da ascensão mística. As primeiras camadas celestiais são regiões aonde a alma vai realizando gradualmente o seu desapego dos vícios corporais. Na região ogdoádica, a alma se encontra com os bemaventurados e canta hinos de louvores ao deus. ${ }^{34}$ Paulo identificou o terceiro céu com o paraíso e ouviu palavras inefáveis nessa dimensão (2 Cor 12,4). DeConick sugere que o logion 50 do Evangelho de Tomé trata de uma experiência de ascensão celestial porque ele contém perguntas e respostas como "De onde vindes?", "Quem sois?" e "Qual é o sinal?" que seriam típicas das experiências de ascensão.

A crença em viagens ao céu era comum no mundo antigo. Os exemplos podem ser encontrados nas literaturas antigas. A crença de que Deus habita nos céus produz nos devotos de diversas religiões o desejo de subir até o mundo divino. ${ }^{35} \mathrm{O}$ contrário também pode ser encontrado nas religiões antigas: a descida aos infernos. Há vários episódios na literatura grega, judaica e cristã de descida aos infernos como a captura do cão Cérbero nos trabalhos de Hércules, ${ }^{36}$ a descida de Jesus à mansão dos mortos (1 Pd 3,19), para citar dois exemplos conhecidos.

A presença das crenças em ascensões no ambiente religioso grego é resultado da influência do Império Persa. Segundo Jan Bremmer, ideias iranianas podem ter chegado através da presença de magi em Atenas num período tardio do século $\vee$ a. $C$. Porém, não podemos nos esquecer das

32 BREMMER, Jan. Descents to Hell and Ascents to Heaven in Apocalyptic Literature. In: COLLINS, John J. The Oxford Handbook of Apocalyptic Literature. New York: Oxford University Press, 2014, p. 349.

33 BREMMER, 2014, p. 349-350.

34 COPENHAVER, 2000, p. 116-117.

35 GOODDER, Paula R. Only the Third Heaven? 2 Corinthians 12, 1-10 and Heavenly Ascent London; New York: T\&T Clark, 2006, p. 23.

36 BULFINCH, Thomas. O livro de ouro da Mitologia: Histórias de deuses e heróis. Tradução de David Jardim. Rio de Janeiro: PocketOuro, 2009, p. 204.

Protestantismo em Revista | São Leopoldo | v. 45, n. 02 | p. 124-133| Jul./dez. 2019 
ideias de Pitágoras e de Platão que podem desencadear nessas considerações sobre a natureza da alma. ${ }^{37}$ No período cristão, essas crenças tinham mais um fundo da filosofia médio-platônica. Esta matriz filosófica imprimiu sua marca também no misticismo do Evangelho de Tomé.

O Antigo Testamento narra a ascensão de Elias aos céus sendo levado por carro e cavalos de fogo (2 Rs 2, 11-12). Embora, se trate de uma experiência diferente, pois a condição de Elias não foi de uma viagem, mas de arrebatamento definitivo, de qualquer modo, as crenças judaicas admitiam esta possibilidade. Na literatura apócrifa judaica, destaca-se a Ascensão de Isaías. É um texto místico que retrata uma viagem do profeta Isaías ao mundo divino. ${ }^{38}$

No círculo cristão, Paulo relata sua experiência de ascensão até o terceiro céu em 2 Coríntios 12, 2-4. Ele afirma que foi arrebatado, mas não sabia se estava no corpo ou fora do corpo e que "ouviu palavras inefáveis, que não lícito ao homem repetir." As experiências possuem elementos comuns como a sensação de sair do corpo, perder os sentidos e obter uma visão e uma revelação sobre assuntos inefáveis. No Apocalipse, João inicia suas visões dizendo que havia uma porta aberta no céu e ele foi convidado para subir até lá. As revelações começaram acontecer a partir desta ascensão celestial (Ap 4, 1).

As experiências herméticas têm um propósito comum ao Evangelho de Tomé. Nesse Evangelho, há uma busca incessante dos discípulos em saber quem é Jesus e quando ele se revelará (logion 37). Os logia de 82 a 85 tratam de uma motivação teológica bastante comum ao autor de Tomé. No 82, Jesus revela quem seu lugar é aquele do fogo e do Reino; no 83, ele diz que as imagens que se manifestam ao homem serão reveladas sob a luz do Pai; e no 84, ele conclui dizendo que quando os discípulos descobrirem suas verdadeiras imagens, ficarão em júbilo, mais surpreendentes ainda são quando descobrirem suas imagens primordiais como seres imortais e não-manifestáveis.

Este conjunto de texto permite amarrar alguns conceitos dispersos no Evangelho de Tomé. $\mathrm{O}$ autoconhecimento tão enfatizado permite que o homem conheça sua verdadeira natureza, aquela que o primeiro homem possuía e que está oculta na vida terrena. A queda de Adão fez o homem perder a sua verdadeira imagem: "Adão saiu de grande força e de grande riqueza, mas ele não foi digno de vós, pois, se ele houvesse sido digno, [não teria] provado a morte" (logion 85).

O autoconhecimento é a chave para a busca da imagem original do homem e a iluminação divina permite o acesso à percepção dessa realidade oculta ao homem terreno. $O$ tema da reunificação ou da recuperação da condição perdida do homem primordial está relacionado ao acesso ao Reino dos Céus. No logion 22, Jesus afirma que entram no Reino dos Céus aqueles que de dois fizerem um e que não sejam nem macho e nem fêmea. No final do logion aparece o termo "imagem". Quem puser uma imagem no lugar de uma outra também entrará no Reino. A troca de imagem indica a mudança da condição carnal para a condição divina como era o homem Adão. A salvação na teologia tomasina é a unificação de tudo que está dividido na condição terrena do homem e consequentemente a união da alma com o divino. As ascensões celestiais fariam sentido dentro do sistema de crenças do Evangelho de Tomé como iluminação do homem para revelar-lhe como era a sua imagem primordial e de como ele poderá retomá-la.

A teologia tomasina foi inspirada pelo mito judaico da queda de Adão. Segundo essa crença, inicialmente Adão era um ser andrógino e depois se dividiu em homem e mulher. A divisão de Adão

37 BREMMER, 2014, p. 349.

38 PIOVANELLI, Pierluigi. 'A Door into Alien World': Reading the Ascension of Isaiah as a Jewish Mystical Text. In: BREMMER, Jan N.; KARMAN, Thomas R.; NIKLAS, Tobias. The Ascension of Isaiah. Leuven: Peeters, 2016, p. 119120.

Protestantismo em Revista | São Leopoldo | v. 45, n. 02 | p. 124-133| Jul./dez. 2019

Disponível em: <http://periodicos.est.edu.br/index.php/nepp> 
o enfraqueceu e o levou à queda. Muitos textos de Nag Hammadi compartilham desse mito. ${ }^{39} \mathrm{~A}$ crença vislumbra a condição de unidade do homem primordial como a completude do ser. O logion 85 expressa a crença na condição inicial de Adão como positiva. Ele veio a ser de "grande força e de grande poder". Portanto, salvação para a teologia tomasina é retornar à condição de unidade porque seus atributos são a imortalidade e a divindade. As palavras secretas de Jesus, anunciadas pelo prólogo do evangelho, conduzem à unificação e, consequentemente, à deificação.

O Poimandres traz a descrição do ser humano também como andrógino e duplo. A natureza andrógina é herança da semelhança com o divino $(\mathrm{CH}, 15)$. Os seres humanos eram andróginos e parte deles se dividiu em macho e fêmea $(\mathrm{CH} 1,18)$. Porém, a dupla natureza do homem é compreendida na constituição de corpo e de alma $(\mathrm{CH} 1,15)$. A mortalidade afeta o homem e o torna refém do destino. A revelação da sabedoria hermética tem o propósito de instruir a respeito de sua natureza e da via para atingir a deificação. ${ }^{40}$ Essas crenças permitem determinar a convergência de vários conceitos entre hermetismo e o cristianismo do Evangelho de Tomé.

\section{Considerações finais}

O Evangelho de Tomé compartilha crenças comuns aos dois documentos hermetistas, isto é, ao Corpus Hermeticum e Um Livro Sagrado de Hermes Trismegisto a Asclépio. Apesar das informações de que havia adeptos do hermetismo na região de Edessa, o ambiente redacional do Evangelho, e da existência dos tratados hermetistas na biblioteca de Nag Hammadi, é difícil determinar a influência. As crenças discutidas neste artigo foram compartilhadas também por outros movimentos filosóficos e religiosos da antiguidade, inclusive, o médio-platonismo.

A discussão sobre a possível influência do hermetismo sobre o Evangelho de Tomé fortalece a visão já consolidada entre os estudos sobre o cristianismo primitivo de que o movimento cristão se desenvolveu dentro de uma diversidade cultural e religiosa muito grande e não esteve imune a essas crenças.

\section{Referências}

BREMMER, Jan. Descents to Hell and Ascents to Heaven in Apocalyptic Literature. In: COLLINS, John J. The Oxford Handbook of Apocalyptic Literature. New York: Oxford University Press, 2014.

BULFINCH, Thomas. O livro de ouro da Mitologia: Histórias de deuses e heróis. Tradução de David Jardim. Rio de Janeiro: PocketOuro, 2009.

BULL, Christian H. Ancient Hermetism and Esoterism. Aries, Journal for the Study of Western Esotericism, v. 15, p. 109-135, 2015.

BULL, Christian H. Hermes between Pagans and Christians: The Nag Hammadi Hermetica in Context. In: LUNDHAUG, Hugo; JENOTT, Lance. The Nag Hammadi Codices and Late Antique Egypt. Studien und Texte Antike und Christentum, v. 110. Tübingen: Moher Siebeck, 2018.

COPENHAVER, Brian P. Corpus Hermeticum y Asclepio. Traducción de Jaume Pòrtulas y Cristina Serna. Madrid: Ediciones Siruela, 2000.

39 MIROSHNIKOV, Ivan. The Gospel of Thomas and Plato: A Study of the Impact of Platonism on the "Fifth Gospel". Helsinki: Unigrafia, 2016, p. 86.

40 COPENHAVER, 2000, p. 114-115.

Protestantismo em Revista | São Leopoldo | v. 45, n. 02 | p. 124-133| Jul./dez. 2019

Disponível em: <http://periodicos.est.edu.br/index.php/nepp> 
COPENHAVER, Brian P. Hermetica: The Greek Corpus Hermeticum and the Latin Asclepius in a new English translation, with notes and introduction. Cambridge: Cambridge University Press, 2000.

DECONICK, April. Seek to See Him: Ascent and Vision Mysticism in the Gospel of Thomas. Leiden; New York: Brill, 1996.

DEN KERCHOVE, Anna Van. La voie d'Hermès: Pratiques rituelles et traité hermétiques. Leiden; Boston: 2012.

GOODDER, Paula R. Only the Third Heaven? 2 Corinthians 12, 1-10 and Heavenly Ascent London; New York: T\&T Clark, 2006.

HARTIN, Patrick J. The Search for the True Self in the Gospel of Thomas, the Book of Thomas and the Hymn of the Pearl. HTS Theological Studies, Durbanville, 55, 4, p. 1001-1021, 1999.

KUNTZMANN, Raymond; DUBOIS, Jean-Daniel. Nag Hammadi: O Evangelho de Tomé: textos gnósticos das origens do cristianismo. Tradução de Álvaro Cunha. São Paulo: Paulinas, 1990.

MAHÉ, Jean Pierre. Les Definitions d'Hermès Trismegiste à Asclépius. Revue des Sciences Religieuses, t. 50, f. 3, p. 193-214, 1976.

MIROSHNIKOV, Ivan. The Gospel of Thomas and Plato: A Study of the Impact of Platonism on the "Fifth Gospel". Helsinki: Unigrafia, 2016.

PATTERSON, Stephen J. The Gospel of Thomas and Christian Origins: Essays on the Fifth Gospel. Leiden; Boston: Brill, 2013.

PIOVANELLI, Pierluigi. 'A Door into Alien World': Reading the Ascension of Isaiah as a Jewish Mystical Text. In: BREMMER, Jan N.; KARMAN, Thomas R.; NIKLAS, Tobias. The Ascension of Isaiah. Leuven: Peeters, 2016.

QUISPEL, Gilles. The Gospel of Thomas Revisited. In: VAN OORT. Gnostica, Judaica, Catholica: Collected Essays of Gilles Quispel. Nag Hammadi Studies. V.55. Leiden; Boston: Brill, 2008.

STORI, Eliana. Edessa, la città benedetta: alcune note sui primi gruppi cristiani in Siria. Annali di Storia del'Esegesi, v. 29, n. 1, p. 49-61, 2012.

STORI, Eliana. Tommaso in Siria: La Ricenzione del Vangelo secondo Tommaso nella Letteratura Cristiana di Siria (II-V secolo). Università degli Studio di Torino, 2010, p. 42-43. 